\title{
Norrie disease resulting from a gene deletion: clinical features and DNA studies
}

\author{
DIAN DONNAI, R C MOUNTFORD, AND A P READ \\ From the Department of Medical Genetics, St Mary's Hospital, Manchester M13 OJH.
}

SUMmaRY We describe a family in which two boys with Norrie disease have a deletion of the $D X S 7$ locus. The deletion does not extend as far distally as the OTC or DXS84 loci. A full clinical description of the patients is given to help establish the range of manifestations of Norrie disease. There is no evidence of any other $\mathrm{X}$ linked disease in our patients.

Norrie disease (NDP, McKusick No 31060) was originally described as $\mathrm{X}$ linked blindness. ${ }^{1}$ It is characterised by early vascular proliferation (pseudoglioma) in both retinas, atrophic irides, corneal clouding, and cataracts, progressing to shrinkage of the globes (phthisis bulbi). The eye findings are well described, ${ }^{2-5}$ but extraocular abnormalities are less commonly illustrated. Diagnosis is usually made on ophthalmological criteria, but we believe that in many cases the disorder is recognisable on general clinical examination.

Carriers have no visual or auditory signs and until recently counselling was based on pedigree analysis alone. A suggestion of linkage between the NDP locus and the glucose 6 phosphate dehydrogenase locus has not been substantiated. However, in 1985 Gal et at ${ }^{6}$ reported close linkage between NDP and the polymorphic $\mathrm{X}$ chromosomal locus $D X S 7$ defined by the probe L1.28, which lies within or close to band Xp11.3. This linkage has been confirmed. ${ }^{78}$ In one of the seven families studied by Gal et $\mathrm{al}^{7}$ there was a deletion of the DXS7 locus in an affected boy and several female relatives. A second NDP family with a deletion was reported by de la Chapelle et al, ${ }^{9}$ who used the deletion for carrier detection and prenatal diagnosis.

We describe a family where two affected boys have a deletion of the DXS7 locus, which we believe is only the third such family reported. In addition to describing the DNA findings, we present detailed clinical descriptions and review published cases. We hope this will help to establish the range of clinical manifestations of the NDP gene.

\section{Case reports}

V.1 (FIG 1)

V.1 was the first child born to healthy non-consan-

Received for publication 25 June 1987

Accepted for publication 17 July 1987 guineous parents after a normal pregnancy. Delivery was normal and his birth weight was $2.6 \mathrm{~kg}$ at term. His mother noted that his eyes looked cloudy on the eighth day of life. After ophthalmic evaluation a diagnosis of primary hyperplastic vitreous was suggested and his left eye was enucleated at 14 months because of shrinkage, pain, and the possibility of a tumour. Developmental delay was apparent from six months but investigations at that time did not identify the cause. He was referred to the genetic clinic at two years nine months and for the first time the family history of blind distant male relatives was obtained (fig 1). On examination he weighed $8.1 \mathrm{~kg}(<3 \mathrm{rd}$ centile), length $80 \mathrm{~cm}(<3 \mathrm{rd}$ centile), and OFC $44 \mathrm{~cm}(<3$ rd centile). There was a prosthetic left eye and the right eye was shrunken with cataract and corneal clouding. His nasal bridge was narrow and his ears prominent with unfolded helices (fig 2). Reflexes were abnormally brisk in his arms and legs and his tone was increased. He could not sit, crawl, or chew but could hold a cup.

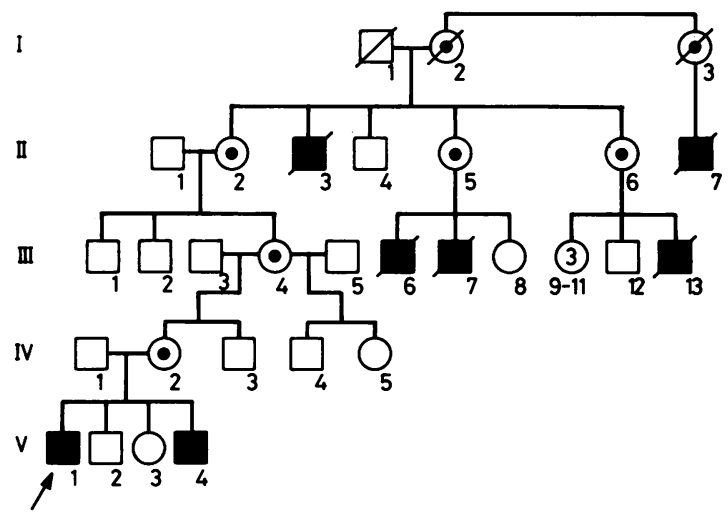

FIG 1 Pedigree of family. 


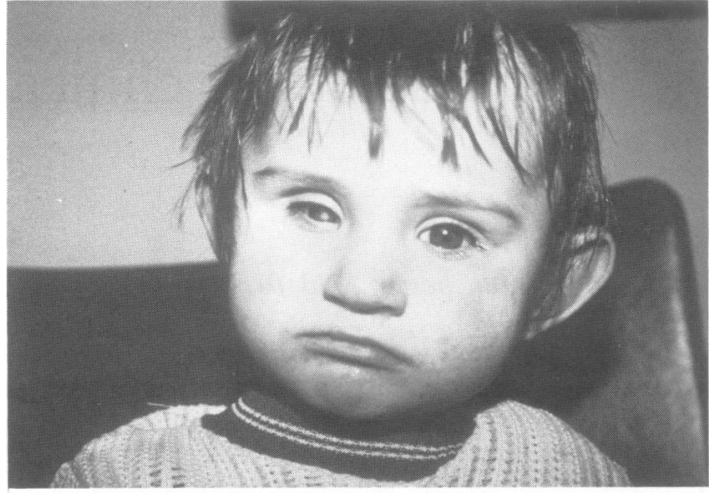

FIG $2 V .1$ at two years nine months. Note sunken right eye with cataract, prosthetic left eye, narrow nasal bridge, and prominent ears.

Auditory brain stem electric response test suggested that his hearing was normal, and an EEG showed no focal abnormalities.

Histological examination of the left eye had shown anterior synechiae, ectropion uveae, a cataractous dislocated lens, and total retinal detachment with proliferation of the pigment epithelium forming a pseudo tumour. There was also mild lymphocytic infiltration and the appearances were thought to be suggestive of intrauterine infection. However, after a clinical diagnosis of NDP was proposed, supported by a possible family history, the microscopical changes were reviewed and considered compatible with this diagnosis.

His progress has been poor. His right eye was enucleated because of pain at eight years. Two seizures occurred but a repeat EEG was normal. At nine years he can sit unsupported but has a postural scoliosis, he feeds himself with a feeder cup and spoon, and he has learnt a little sign language. $\mathrm{He}$ shows pleasure at the sound of his mother's voice and at her touch. He constantly grinds his teeth, thrusts his jaw, chews his fist, and scratches his skin. $\mathrm{He}$ is very thin with poor muscle bulk and cold extremities. His facial features are fine and his ears large and prominent. Length is $102 \mathrm{~cm} \quad(<3 \mathrm{rd}$ centile) and OFC $46.6 \mathrm{~cm}(<3$ rd centile) (figs 3 and 4). His testes are undescended.

\section{v. 2 AND v. 3}

The normal four year old brother and two and a half year old sister of the proband have no visual, auditory, or developmental problems.

v. 4

He was born at 38 weeks' gestation after a normal

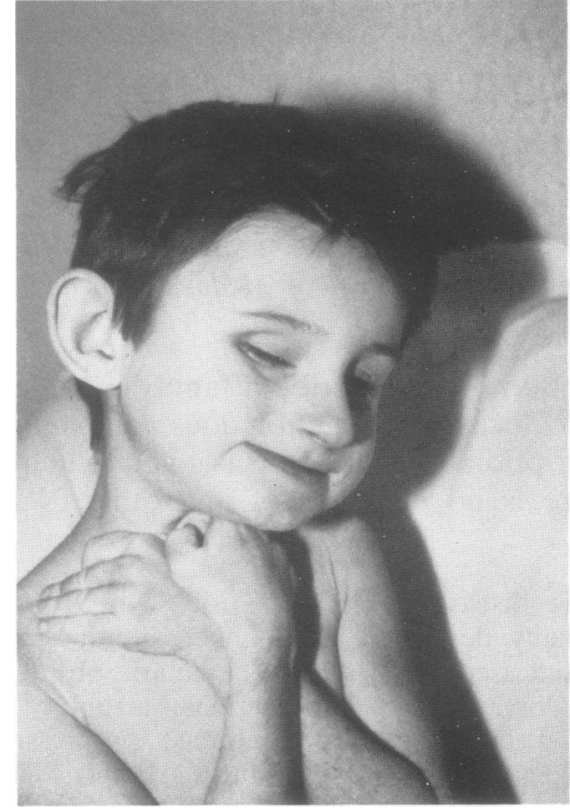

FIG 3 V.1 at nine years. Note narrow nasal bridge, flattened malar region, and thin upper lip.

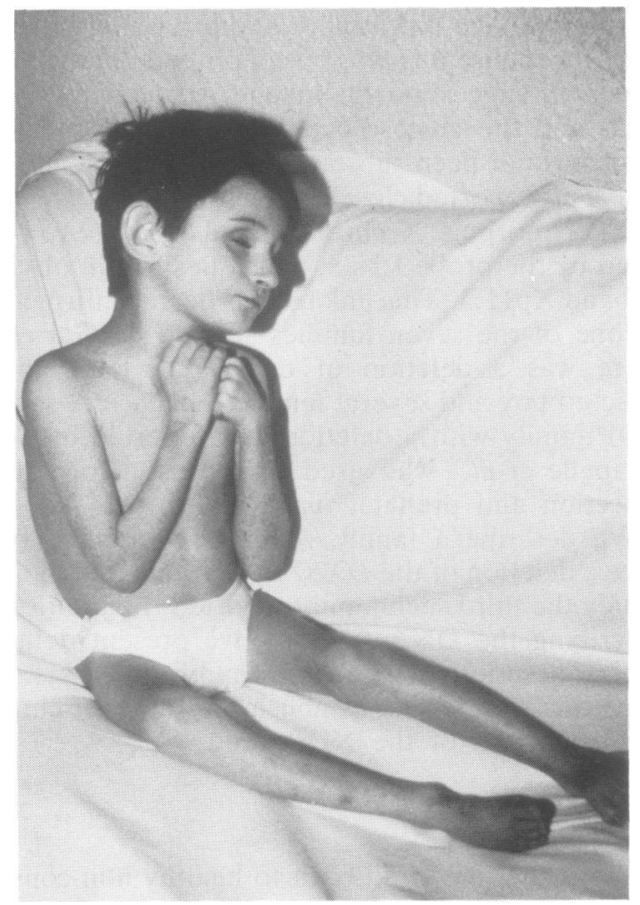

FIG 4 V.1 at nine years. Note poor muscle bulk. 
pregnancy; birth weight was $2.98 \mathrm{~kg}$, OFC $35 \mathrm{~cm}$. His physical resemblance to V.1 was noted by his mother and she suspected eye problems within two weeks of birth. Examination under anaesthetic at one month showed that the right anterior chamber was totally flat with increased vascularisation; the left pupil was dilated and unresponsive with a dense retrolental membrane. At that time intraocular pressures were normal and neither eye was small. He made extremely slow progress and by nine months could make a range of sounds and hold an object placed in his hand. He was floppy and had poor head control but did appear to respond to handling by his parents.

When examined at 17 months his weight was only $5.92 \mathrm{~kg}(<3 \mathrm{rd}$ centile) and he was severely wasted (fig 5). He was facially similar to V.1 and dissimilar to V.2 and V.3. His nose was narrow, his malar area flat, and his ears large. The left eye was enophthalmic and there were bilateral cataracts (fig 6). He was microcephalic (OFC $42.5 \mathrm{~cm},<3 \mathrm{rd}$ centile) and his length was $71 \mathrm{~cm}$ (<3rd centile). Audiological examination showed dull tympanic membranes and there was low compliance and low middle ear pressure on impedence audiometry. He was admitted to hospital for nutritional assessment and

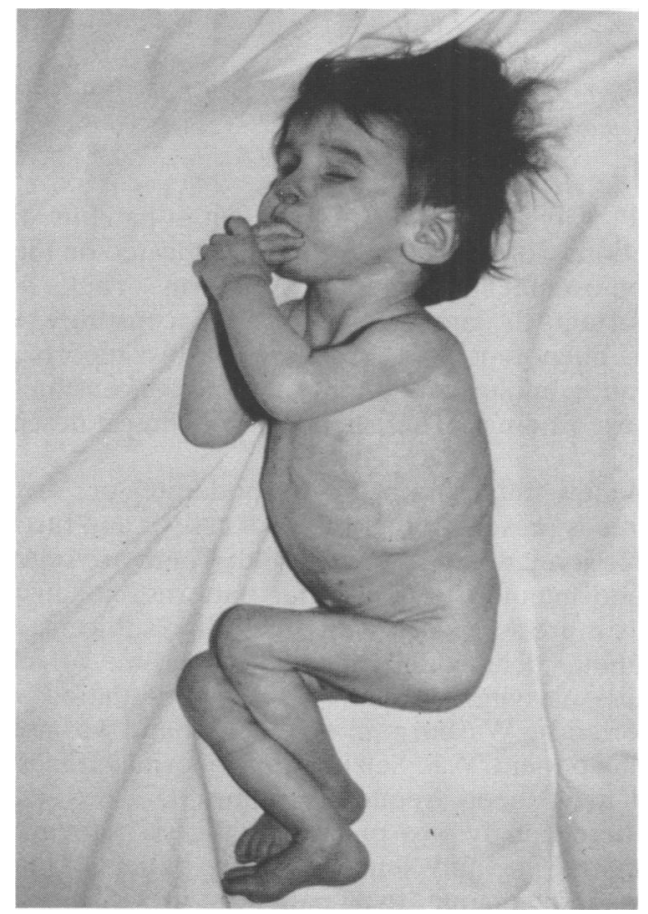

FIG $5 \quad V .4$ at 17 months. Note severe wasting and large ears.

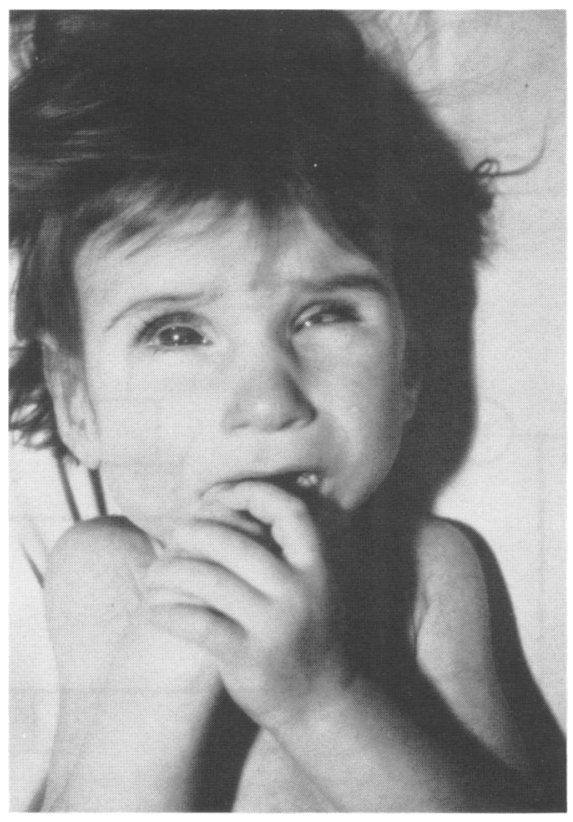

FIG $6 \quad V .4$ at 17 months. Note sunken eyes, narrow nasal bridge, and thin upper lip.

treatment and his weight did increase a little. Periods of decreased awareness and a series of generalised myoclonic jerks were noted but an EEG was normal. His testes are undescended.

\section{3, II. 7, III.6, III.7, AND III.13}

These males were all known to II. 2 who reported that they were blind, had sunken eyes, and died between infancy and adolescence. Developmental retardation was a feature. We were unable to contact this branch of the family or the medical staff involved with them.

\section{Results of investigations}

DNA extraction from peripheral blood leucocytes, restriction enzyme digestion, Southern blotting, hybridisation, and autoradiography were performed as described. ${ }^{10}$ Probes were labelled by hexanucleotide primed synthesis. ${ }^{11}$ DNA probes L1.28 and 754 define the loci $D X S 7$ and $D X S 84$ respectively; OTC is an ornithine transcarbamylase cDNA. The affected boys showed a deletion with probe L1.28 (fig 7), but not with OTC or 754.

The hexose monophosphate shunt pathway in peripheral blood leucocytes: was examined by measuring the increase in NBT reduction after stimulation with phorbol myristate acetate, and the 

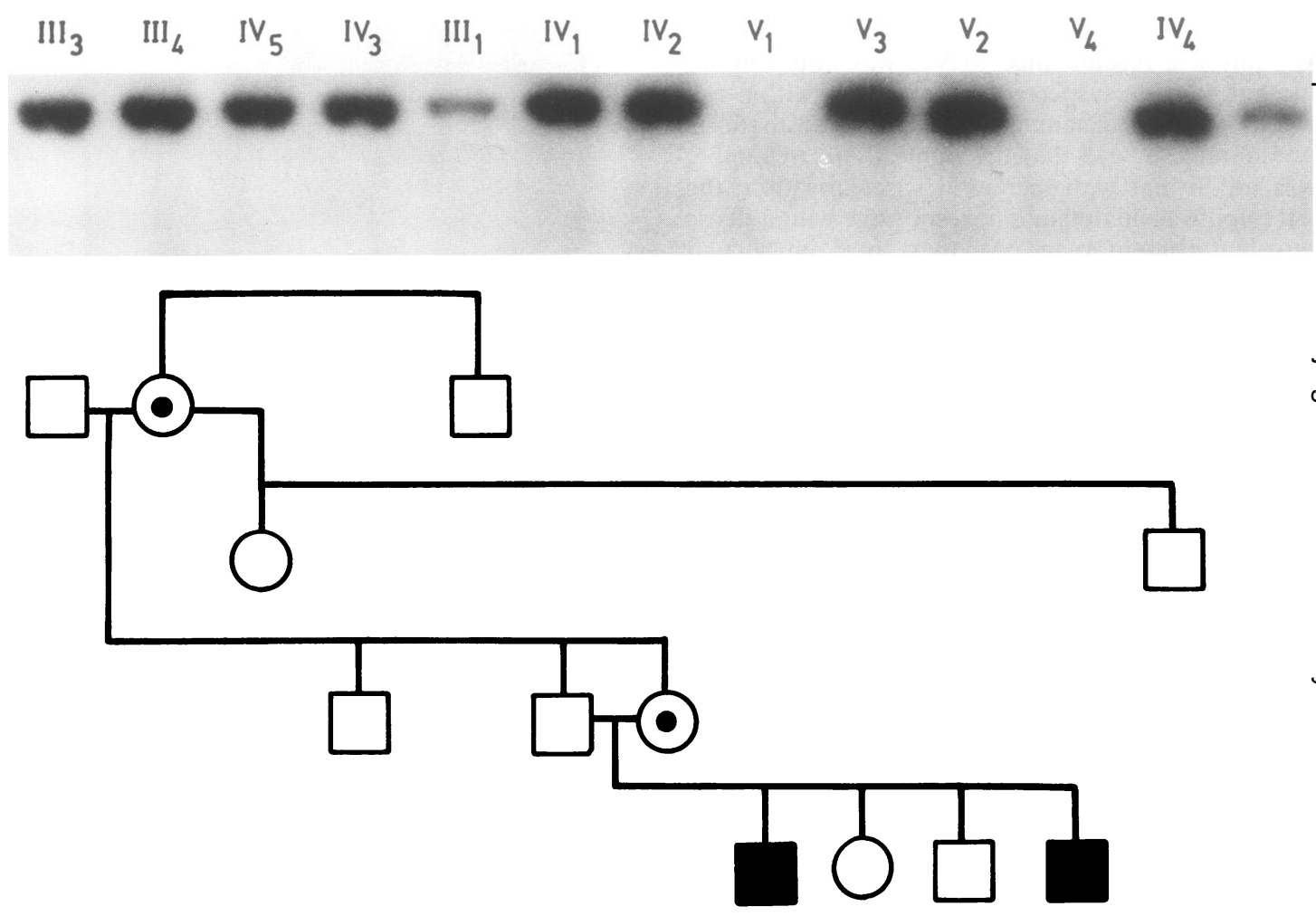

FIG 7 Autoradiograph of TaqI digested DNA of family members hybridised to radiolabelled probe L1.28. DNA from $V .1$ and V.4 does not hybridise with this probe. All other samples show a single $12 \mathrm{~kb}$ band.

increase in the level of enhanced chemoluminescence after stimulation with Zymozan. Results were normal. This excludes any defect similar to chronic granulomatous disease.

Urine amino acid chromatography showed normal results. Serum creatine kinase levels were within the normal ranges for the affected boys and their mother. The platelet count on V.4 was normal, and neither boy had any skin manifestations of Wiskott-Aldrich syndrome. No chromosomal abnormality was visible in cultured lymphocytes from the affected boys and their mother. Electroretinography and fundal examination of the mother did not show any evidence of the carrier state for $\mathrm{X}$ linked retinitis pigmentosa.

\section{Discussion}

Boys with $\mathrm{X}$ chromosome deletions sometimes have phenotypes which combine features of several $\mathrm{X}$ linked diseases. ${ }^{12}$ The discovery of deletions in some but not all NDP patients makes it desirable to distinguish those who may have chromosomal deletions spanning several loci from those with typical
NDP. Any additional features seen in patients with? deletions would then point to genes located on the $\mathrm{X}$ chromosome near to the NDP locus. Thus, it is important to know what features constitute the usual phenotype of Norrie disease. Most reports are in ophthalmological publications and concentrate on음 the eye findings. There are few full clinical descriptions.

Mental retardation of a moderate or severe $D$ degree is present in two-thirds of cases, ${ }^{2}$ and further regression is sometimes reported. There are reports of odd manneristic behaviour patterns, not neces sarily those associated with other blind subjects, and psychotic behaviour is described in some affectedw males surviving to adult life. Self mutilation was reported by Warburg ${ }^{2}$ in one patient and was notedo in our patient V.1. Seizures or abnormal EEGs ok্ both have been frequently reported.

Microcephaly was present in the six patients of Moreira-Filho and Neustein, ${ }^{5}$ in the patient of Gal $e \stackrel{P}{2}$ $a l,{ }^{13}$ and in our two patients. OFCs are noţ mentioned in most reports even where there was severe mental retardation, but there was an abnor 
mal pneumoencephalogram indicating cerebral atrophy in two of Warburg's patients, ${ }^{2}$ and brain examination at necropsy of another of her patients showed abnormalities of the cerebral cortex and mesencephalon.

Birth weights in reported cases were generally normal. In both our patients very poor muscle bulk was a feature, in spite of dietary treatment. This was also a feature in other reports; Hansen ${ }^{3}$ reported lower limb atrophy in his patients at 33 months and Warburg $^{2}$ mentioned weight loss in the proband of her family A.

Moreira-Filho and Neustein ${ }^{5}$ thought their family atypical because of hypogonadism manifested by cryptorchidism and low serum testosterone, but cryptorchidism was a feature in our patients, and was coupled with delayed puberty in the patient of Gal et al. ${ }^{13}$

Descriptions of physical appearance are generally not given in published reports; we have been able to identify only one published photograph of the whole face of an affected male. ${ }^{2}$ He has a narrow nasal bridge, the appearance of hypotelorism accentuated by the shrunken globes, flattened malar regions, and a thin upper lip. His ears are large and prominent. A lateral view of an affected male is shown by Moreira-Filho and Neustein, ${ }^{5}$ showing microcephaly, large ears, and sunken eyes. Photographs of part of the faces of other affected males ${ }^{2} 4$ also show narrow nasal bridges. Our patients had fine features with narrow nasal bridges, hypotelorism, flattened malar regions, thin upper lips, and large ears. They look similar to one another and to the case of Warburg, ${ }^{2}$ but totally dissimilar to their normal sibs.

There is no evidence that our patients had any $\mathrm{X}$ linked disease in addition to Norrie disease. Specifically, they did not have Duchenne muscular dystrophy, chronic granulomatous disease, WiskottAldrich syndrome, or any detectable abnormality of amino acid metabolism. Gal et al ${ }^{13}$ suggest that several features of their patient (severe mental retardation, growth disturbances, disorders of sexual development and maturation, and a clinical history suggestive of an immune defect) have never been reported in typical NDP, and thus suggest that other disease loci are deleted. This implies that those reported patients who do show some of these features do so because of a deletion. It is not yet clear what proportion of NDP families have a deletion of $D X S 7$. The published reports ${ }^{6-9} 13$ would suggest three out of 16 , but non-deleted males in families uninformative for linkage are not likely to be reported. Perhaps $10 \%$ of NDP families may be deleted for $D X S 7$; deletion of the NDP locus itself may of course be more frequent. Thus, it remains to be determined how much of the clinical variability is due to some families having deletions. However, even within families the phenotype can be very variable; in Warburg's study ${ }^{2}$ males with mental retardation and failure to thrive had affected relatives without these features.

Before appropriate DNA studies can be performed, a clinical diagnosis must be made. Our first patient was incorrectly diagnosed as having a disorder with little or no genetic component. The typical eye findings are well described in almost all reports, but we suggest that the gestalt of Norrie disease may also help in diagnosis. The differential diagnosis includes retrolental fibroplasia of premature babies subjected to oxygen therapy, intrauterine infections especially toxoplasmosis, retinoblastoma, primary hyperplastic vitreous, and perhaps Lowe's syndrome.

In our family the affected boys are deleted at the $D X S 7$ locus but the deletion does not extend distally as far as the OTC or DXS84 loci. The obligate carriers III.4 and IV.2 must be hemizygous for DXS7; the females at risk IV.5 and V.3, might be hemizygous or homozygous. We cannot measure gene dosage on Southern blots reliably enough for diagnostic use; in addition the husband of each obligate carrier has the same $D X S 7$ type as his wife, which rules out the possibility of seeing aberrant segregation of DXS7 types (apparent non-maternity) in daughters who have inherited the deletion. Thus, we are unable to assess the carrier status of IV.5 and V.3 using L1.28.

Family members are informative for RFLPs at the OTC and DXS84 loci. IV.5 has the opposite OTC allele, and V.3 the opposite DXS84 allele, to the deleted $X$ in the affected boys. This suggests that neither girl carries the deletion. Unfortunately, recombination makes this prediction unreliable. The peak lod scores for $\mathrm{L} 1.28$ versus OTC and DXS84 are at $\theta=0.15$ and 0.20 respectively. ${ }^{14}$ The asymmetry of the lod score curve means that the average error rate is rather greater than these recombination fractions (J H Edwards, 1987, personal communication), even assuming the NDP locus does not lie significantly proximal to $D X S 7$. Therefore, IV.5 and V.4 have an appreciable risk of carrying the deletion, and they will be offered fetal sexing and L1.28 studies in any pregnancies.

Immunological studies on the affected boys were carried out by Dr Richard Pumphrey. Probes L1.28 and 754 were a kind gift from Professor Peter Pearson, and the OTC probe from Dr Kay Davies. RCM is supported by a Special Medical Development grant from the UK Department of Health and Social Security. 


\section{References}

' Norrie G. Causes of blindness in children. Acta Ophthalmol (Kbh) 1927;5:357-86.

2 Warburg M. Norrie's disease, a congenital progressive oculoacoustico-cerebral degeneration. Acta Ophthalmol [Suppl] (Kbh) 1966;89:1-147.

${ }^{3}$ Hansen AC. Norrie's disease. Am J Ophthalmol 1968; 66:32832.

4 Townes PL, Roca PD. Norrie's disease (hereditary oculoacoustico-cerebral degeneration). Am J Ophthalmol 1973;76: 797-803.

5 Moreira-Filho CA, Neustein I. A presumptive new variant of Norrie's disease. J Med Genet 1979;16:125-8.

${ }^{6}$ Gal A, Stolzenberger C, Wienker TF, et al. Norrie's disease: close linkage with genetic markers from the proximal short arm of the X chromosome. Clin Genet 1985;27:282-3.

${ }^{7}$ Gal A, Bleeker-Wagemakers L, Wienker TF, Warburg M, Ropers HH. Localisation of the gene for Norrie disease by linkage to the DXS7 locus. HGM8. Cytogenet Cell Genet 1985;40: 633.

${ }^{8}$ Kivlin JD, Sanborn GE, Wright E, Cannon L, Carey J. Further linkage data on Norrie disease. Am J Med Genet 1987;26:733-6.

' De la Chapelle A, Sankila EM, Lindlof M, Aula P, Norio R. Norrie disease caused by a gene deletion allowing carrier detection and prenatal diagnosis. Clin Genet 1985;28:317-20.

10 Maniatis T, Fritsch EF, Sambrook J. Molecular cloning: a lab $\vec{\Rightarrow}$ oratory manual. Cold Spring Harbor, NY: Cold Spring Harbour Laboratory, 1982.

"Feinberg AP, Vogelstein B. A technique for radiolabelling DNA restriction endonuclease fragments to high specific acti $\frac{\bar{C}}{\bar{D}}$ vity. Anal Biochem 1983;132:6-13.

12 Francke U, Ochs HD, de Martinville B, et al. Minor Xp21 chromosome deletion in a male associated with expression of Duchenne muscular dystrophy, chronic granulomatous disease, $\infty$ retinitis pigmentosa and McLeod syndrome. Am J Hum GeneT 1985;37:250-67.

13 Gal A, Wieringa B, Smeets DFCM, Bleeker-Wagemakers L, $\vec{\oplus}$ Ropers HH. Submicroscopic deletion of the $X$ chromosome explains a complex genetic syndrome dominated by Norric dis ease. Cytogenet Cell Genet 1986;42:219-24.

14 Goodfellow PN, Davies KE, Ropers HH. Report of the commit tee on the X and Y chromosomes. HGM8. Cytogenet Cell Genex 1985;40:296-352.

Correspondence and requests for reprints to $\operatorname{Dr} \mathrm{D}_{-}^{\mathrm{O}}$ Donnai, Department of Medical Genetics, StTा Mary's Hospital, Hathersage Road, Manchestero M13 0JH. 